\title{
Design of tank car's explosion-proof valve driven-detection device
}

\author{
Qing Li ${ }^{1, \mathrm{a}}$, Hai-Jian Zhong ${ }^{2}$, Ye-Qing Sun ${ }^{1}$, Xin-Hua Xia ${ }^{2}$, \\ Ge Shi ${ }^{1}$, Mu-Da Jin ${ }^{2}$, Ren-Yuan Tong ${ }^{1}$, Zhi-Peng Zhao ${ }^{1, b_{*}}$ \\ ${ }^{1}$ College of Mechanical and Electrical Engineering, China Jiliang University, \\ HangZhou, ZheJiang, China \\ ${ }^{2}$ Zhejiang Provincial Special Equipment Inspection And Research Institute, \\ HangZhou, ZheJiang, China \\ aq13306532957@163.com, ${ }^{\text {b } 812970581 @ q q . c o m ~}$
}

Keywords: tank car; valve driven device; mechanical structure; simulation.

Abstract. Tank car accidents happened in china frequently, it is harmful to the ecological environment and the economic development. Tank testing is an effective guarantee for safe transportation of tank car. At present, the most efficient way is entering into the tank to inspect it, so, the harmful gas must be exhausted before entering into the tank. However, existing tank gas exhaust method can't discharge gas completely and that is a threat to the safety of inspectors. In the paper, a new explosion-proof valve driven-detection device of tank car is designed, it can exhaust gas in tank car under the cooperation with other components and detect the internal pressure of tank at the same time and relief pressure dynamically. This article made a detailed introduction to driven device's mechanical structure and carry out a simulation for the strength of its keypoint.

\section{Introduction}

With the development of china, devices which have the function of pressure control take part in project engineering widely. At present, special chemical gas has to be transported by tank car whose tank should be sealed. The tank is the core of tank car which loads chemical gas as pressure vessel[1]. Therefore, the pressure-relief device of tank is important. Explosion-proof valve is the most important part of the tank. In this paper, the device that designed to driven the explosion-proof valve can relief pressure dynamically with a pressure sensor and exhaust harmful gas. So, this system is significant to the regular inspection of tank car and can guarantee the life safety of inspectors, decreases the risk of chemical gas transport as well.

\section{Overall Structure of System}

For exhausting gas in tank and detecting the tension of the valve, a explosion-proof valve driven-detection device is designed in this paper. The device is mainly contains three parts which are valve driven device, tension detection device and explosion-proof design. The overall structure of explosion-proof valve driven-detection device is shown in Fig.1.

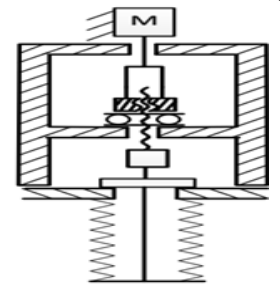

Fig. 1 overall structure of explosion-proof valve driven-detection device 
As fig. 1 shown, it mainly uses a part of guilde screw to convert the rotate of guilde screw to rectilinear motion. [2] In this design, the output torque of motor is amplified by the reduction gear and rotating guilde screw by coupler. At the same time, rotation of guilde screw converts to rectilinear motion with some mechanical structure which keeping the guilde screw from rotating.

Tension detection system is mainly contains sensors and related sampling circuit. The tension sensor described above can connect the guilde and the cover of the valve. The connected relation of each component can be seen in fig. 2 .

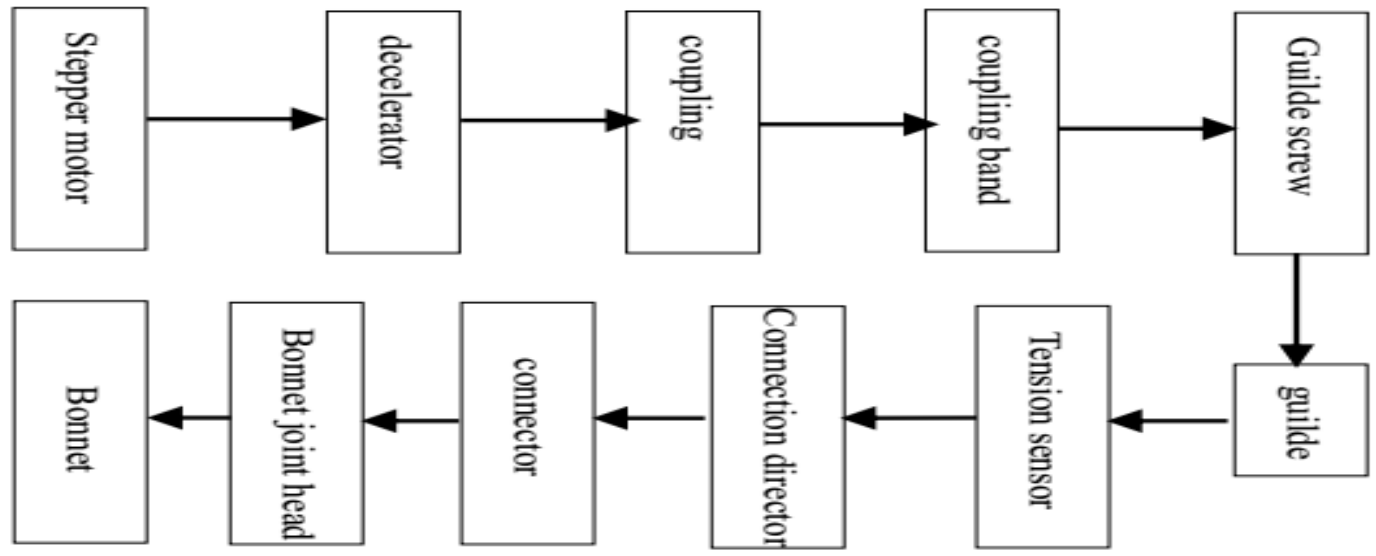

Fig. 2 connected relation of each component

electric components of the device must be isolated from combustible gases. Therefore, all the electriferous component must be sealed in the space that formed by connection director and oil seal. Whole assembly drawing is in fig.3.

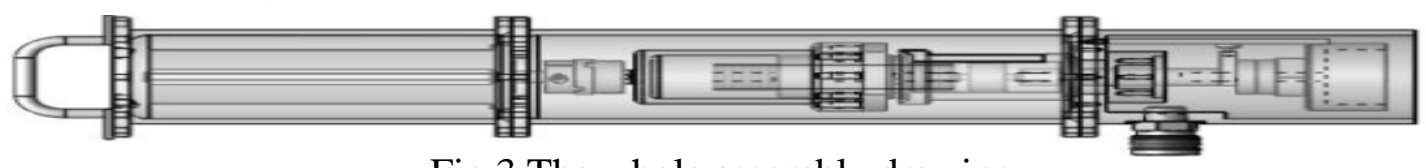

Fig.3 The whole assembly drawing

\section{Mechanical design of relief valve driven device}

\section{guilde screw pair}

For the airtightness and the feasibility of the structrue, it uses a part of guilde screw to convert the rotate of guilde screw to rectilinear motion. [3] Therefore, linear motion of a ball screw trip is short and load is large. $3 \mathrm{~d}$ structure of the guilde screw pair is shown in fig. 4 .

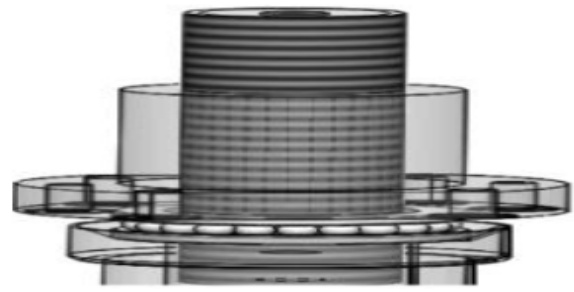

\section{Driving force transmission mechanism}

Fig.4 structrure of guilde screw pair

The driving force transmission mechanism is designed into a telescope-feed because the rotation of ballscrew need a controllable driving force. It has the advantages of convenient connection of guilde screw with nut column and remaining a space for the motion of guilde. The overall structure of the installation is shown in figure 5 . 


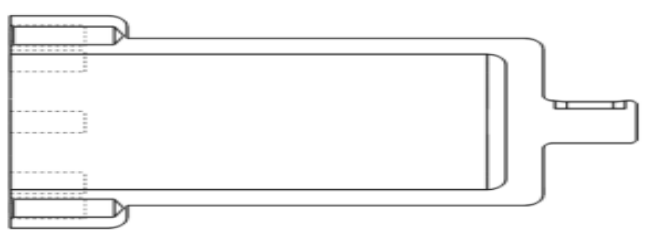

Fig. 5 driving force transmission mechanism

As shown in fig.6, through analyzing static stress simulation module in SolidWorks, it is a stress distribution, the maximum stress is $1.58 * 10^{7} \mathrm{~N} / \mathrm{M}_{2}$, stainless steel yield stress is $2.0 * 10^{8} \mathrm{~N} / \mathrm{M}_{2}$, it fully meets the design requirements.
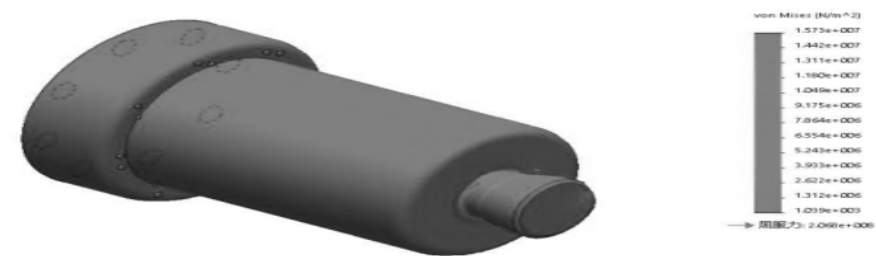

Fig.6 stress distribution pattern of driving force transmission mechanism

\section{Assembly mechanism of tension sensor}

In order to guarantee gulide screw's rotary motion convert into linear motion. It needs to keep the guilde away from rotating. The 3D view of relevant components are shown in figure 7 :

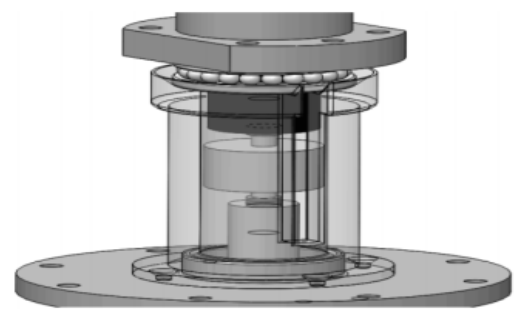

Fig. 7 tension sensor assembly 3D drawing

The two side of tension sensor are connect with the guilde and connection director with the thread[6]. Tension sensor was installed in a supporting mechanism. and a groove was designed for the signal and power wires of the tension sensor so that wires can run with thesensor together. The groove can avoid breaking the wires in mechanism of tension sensor.

\section{Explosion-proof sealing mechanism}

The explosion-proof valve driven-detection device will work in the environment which is full of combustible gases. A flameproof scheme is present in this paper, sealing a axis by two oil seals and filling the gap between oil seals by ubricating liquid. The structrue of the flameproof mechanism likes fig. 8. Sealed module is mainly composed of skeleton oil seals, guiding axis, oil-free foil and support sleeve.

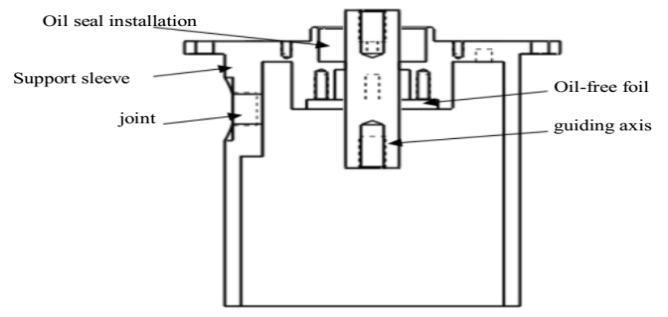

Fig.8 structrue of the flameproof mechanism 


\section{The development of the pull test system}

\section{The sensor selection}

Due to the specialty of this research, sensor should be small in structure and accurate and has a large measurement range as well. According to those requirements above, the tension sensor produced by the BSLM company is used in this design.

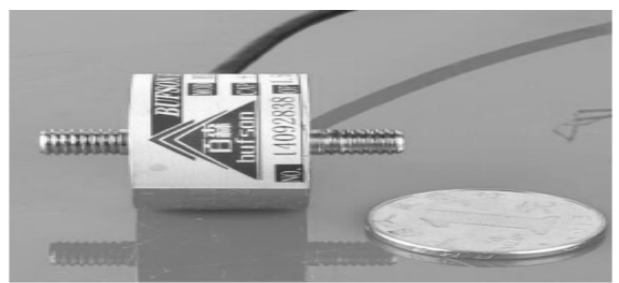

The sensor is shown in fig.9.

\section{The signal processing circuit design}

Tension sensor output signal level is millivolt, it is difficult to display, record, control or sampling that kind of signal directly. In this paper[4-5], AD620 chip is used to realize the precise amplification of signal. It uses the $5^{\text {th }}$ pin of AD620 to keep the balance of the whole circuit, the implement of reference voltage is by the resistive subdivision with $\mathrm{R} 17$ and $\mathrm{R} 18$, and it was isolated by a voltage follower. Two capacitances filter the power signal. The stability of the whole system relies on the precise resistance. Whole circuit is shown in fig. 10.

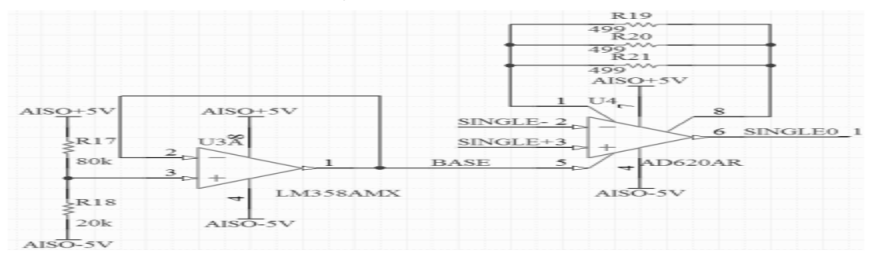

Fig. 10 Precision amplifying and voltage adjustment circuit

Sensor of this system is composed of resistance strain gauge, so amplified signal is still a dc signal. So, it uses a low pass filter in the signal process part. The specific circuit is shown in fig. 11.

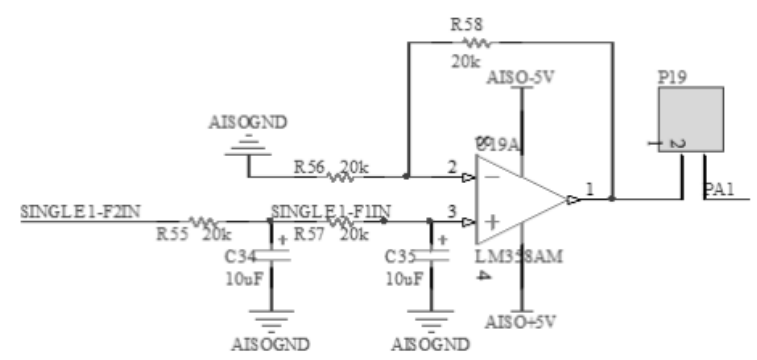

Fig.11 low-pass active filter

\section{Conclusions}

In this paper, the research of relief valve driven-detection system can drive the explosion-proof valve and detect the tension during the opening and close of the valve. It realizes the exhaustion of gases in tank car and tank valve inspection.

\section{Acknowledgements}

This work was financially supported by the science and technology planning project of state Administration for Quality Supervision and Inspection and Quarantine(Project number:2014QK198) 
and Scientific research projects of Zhejiang province quality and technical supervision system(Project number:20160225)

\section{References}

[1] Tang Lei. The Stimulation Research of Road Transport Management Policy of Hazardous[D]. Dalian Maritime University,2010.

[2] XU Yi-fei;FENG Hu-tian;OU Yi. Comprehensive Stress Analysis of Foyr Typical Screw Loading Ways[J]. Modular Machine Tool \& Automatic Manufacturing Technique, 2015, (2): 30-34.

[3] XU jiqin, Liu Wen. The installation of the ball screw on the nc machine tool and use it [C]. Manufacturing Automation .2000:256 257.

[4] Zhang tan-qin. Research on the system of Electrnic Weighing for Pouring based on ARM[D]. Nanjing University of Aeronautics and Astronautics, 2008.

[5] $\mathrm{Xu}$ ZhengZhao. The Design of Strain Micrometer Sensor's Measurement System[D]. ChongQing university, 2014.

[6] YUAN Cui ,LI Yue . Several Issues of Gasoline Engine Oil Seal Design and Assembly [J]. Equipment Manufacturing Technology, 2010,(3):108-110. 